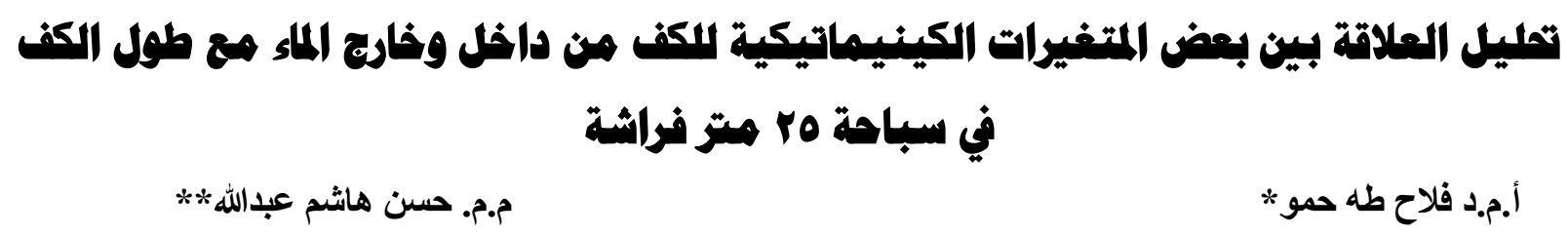

ثرع الألعاب الفردية/كلية التربية الرياضية/جامعة الموصل/العراق.yahoo.com.hamo@yahom

* * كلية التربية الاساسية/جامعة السليمانية/السليمانية/العراق.

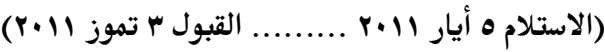

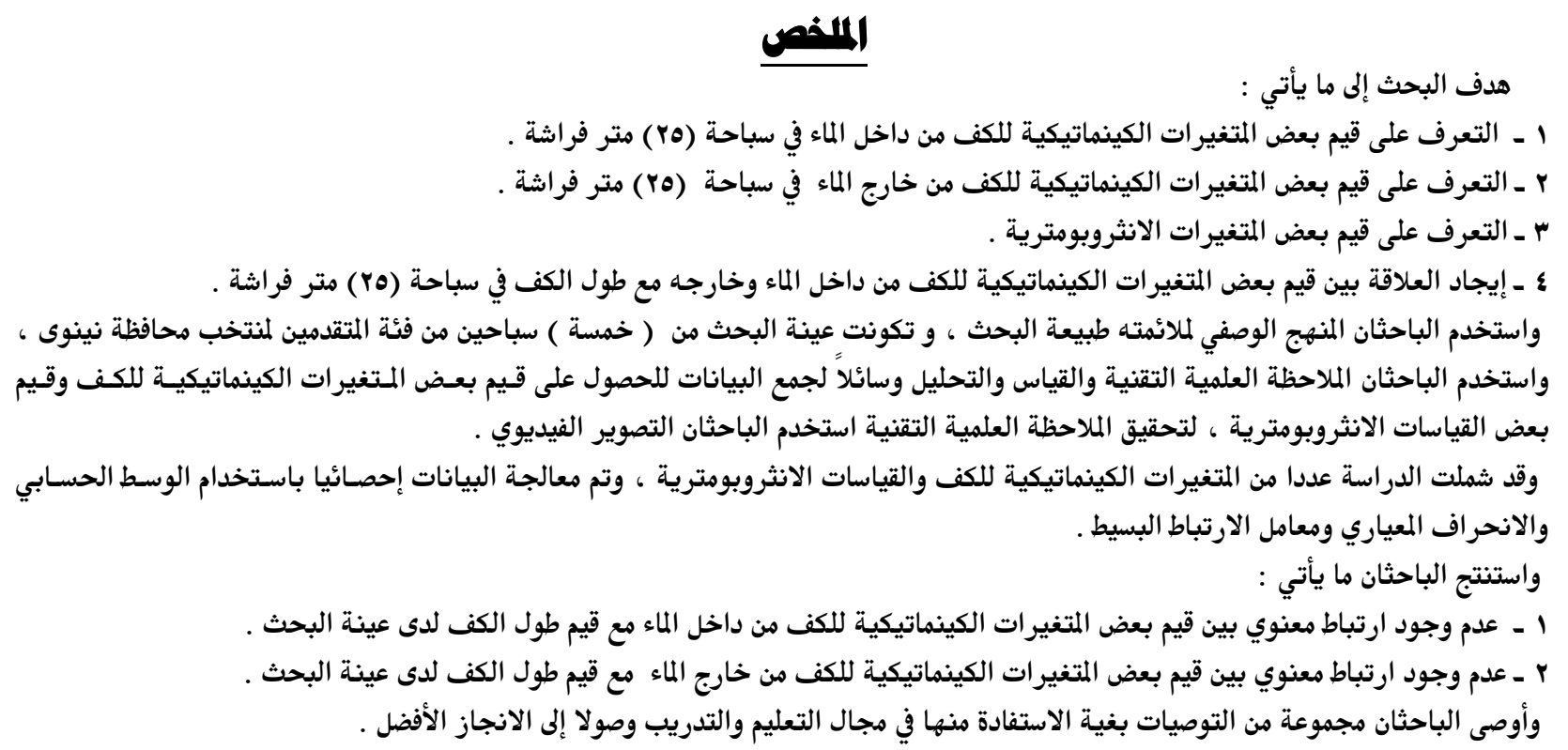

\title{
Analysis of the relationship between some biokinematics variables of hand palm from inside and above water with the length of hand palm in the $25 \mathrm{~m}$ butterfly swimming
}

Asist.prof.dr.Falah.T.Hammo

Hasan.H.Abdullah

\section{The research aimed at :}

\section{$\underline{\text { Abstract }}$}

1. Recognizing the values of some biokinematics variables of hand palm from inside water in the $25 \mathrm{~m}$ butterfly swimming .

2. Recognizing the values of some biokinematics variables of hand palm from above water in the $25 \mathrm{~m}$ butterfly swimming .

3. Recognizing the values of some anthropometric measurement .

4. Finding the relationship between the values of some biokinematics variables of the hand palm from inside and above water with the length of the hand palm in the $25 \mathrm{~m}$ butterfly swimming .

The descriptive method was used . the sample included ( 5 ) swimmers of the senior group of Nineveh team . the technical scientific observation, analysis and measurements were used as means to collect the data and then to obtain some of the biokinematics variables values and some anthropometric measurements values, to achieve the technical scientific observation accurately, the videography was used . the study included a number of biokinematics variables of the hand palm and anthropoetric measurements . the data have been processed statistically by using the mean, standard deviation and simple correlation .

the researchers concluded the following :

1 - There were no significant correlations between biokinematics variables values of hand palm from above water and the length of the hand palm values .

2 - There were no significant correlations between biokinematics variables values of hand palm from inside water and the length of the hand palm values .

The researchers recommended some recommendations to be utilized in the learning and coaching to get the best performance . 


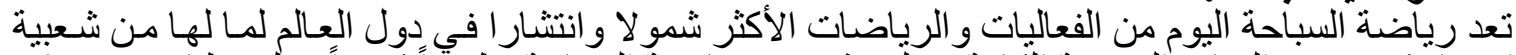

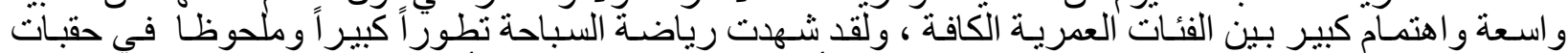

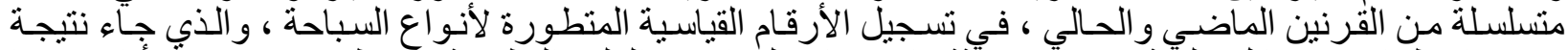

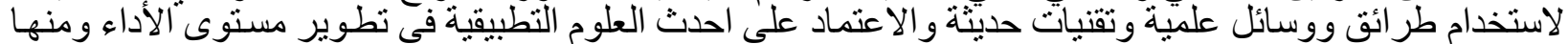

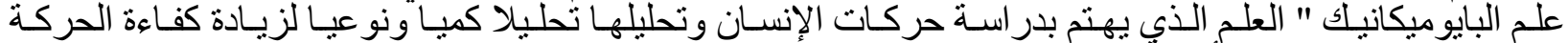

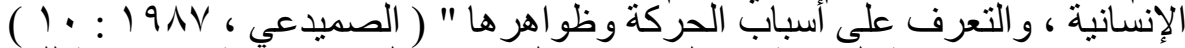

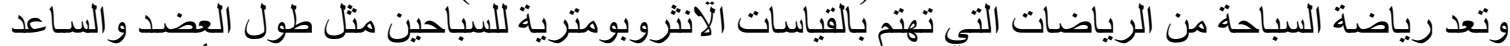

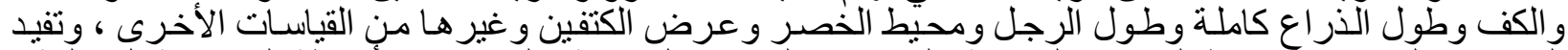

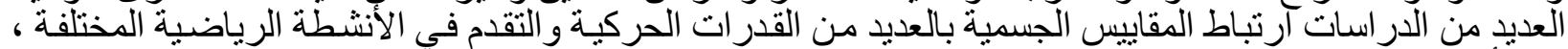

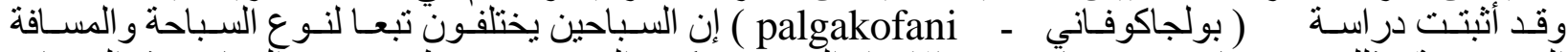
التخصصية وذلك في صفات عدة منها مستوى الإعداد البدني ونركيب الجسم ، ويرتبط تخصص إنس النباح بهذه الصفات

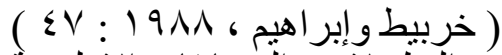

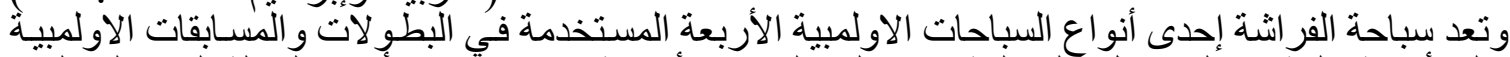

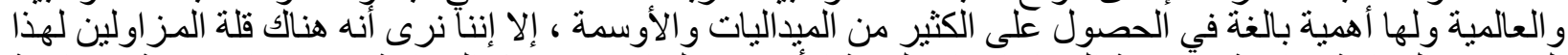

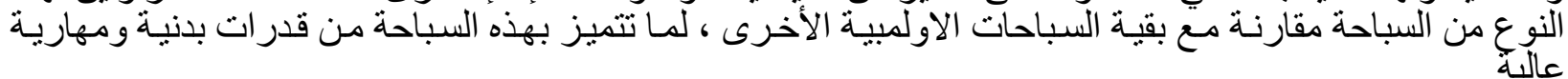

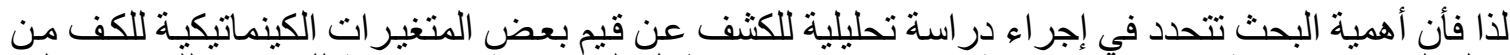

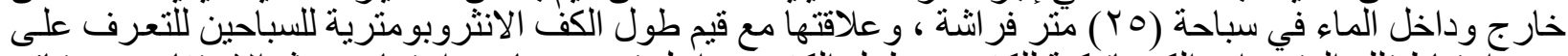
مدى ارتباط تلك المتغير ات الكينماتيكية للكف مع طول الكف من اجل توضي توضيحها ودر استهاو ومن ثم الاستفادة من نتائج

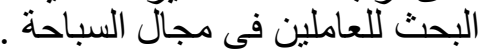

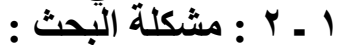

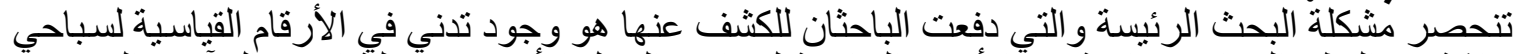

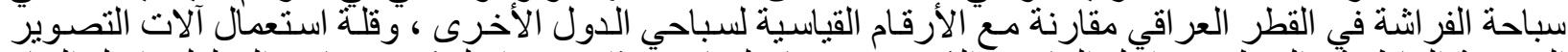

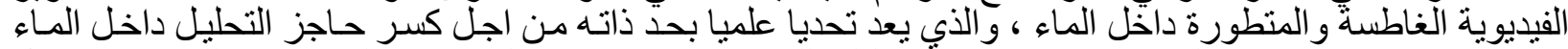

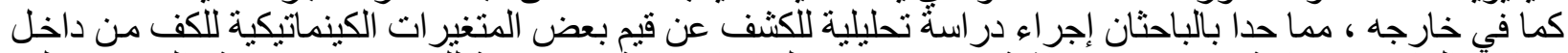

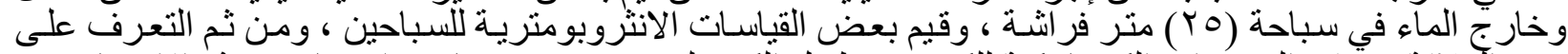

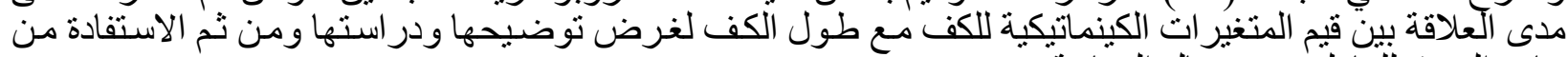

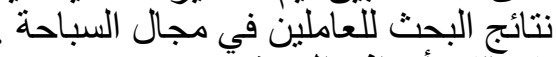

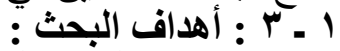

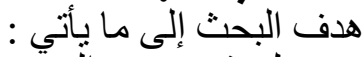

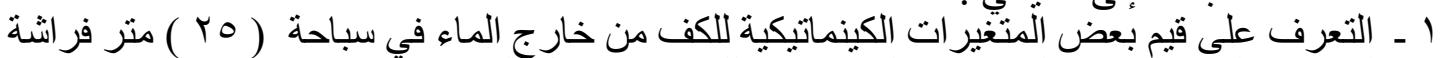

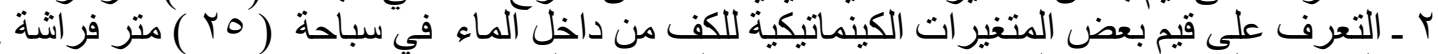

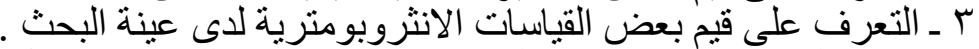

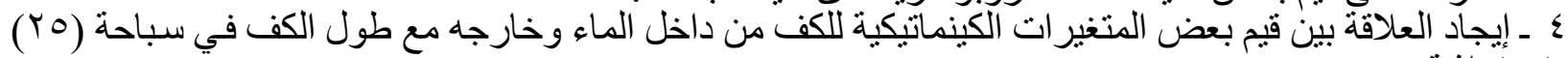
متر فر اشة إنة

\section{|}

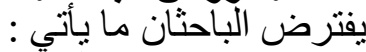

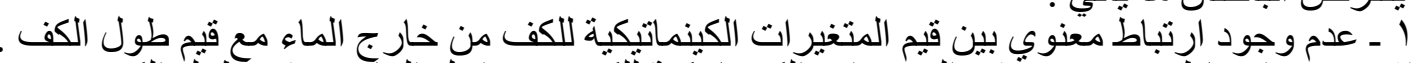

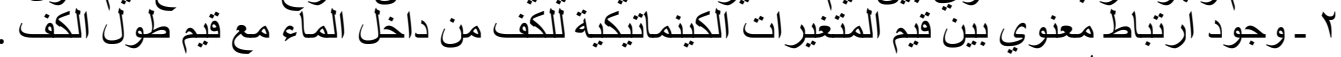

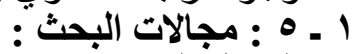

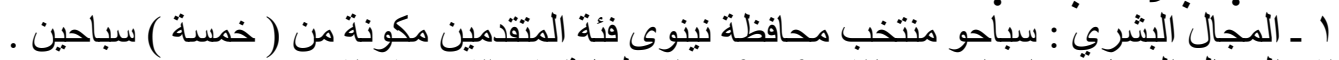

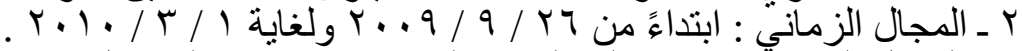

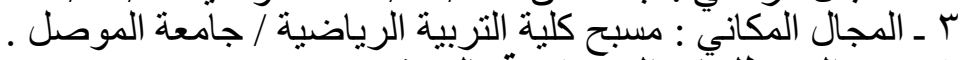

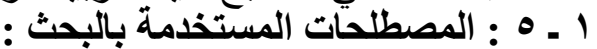

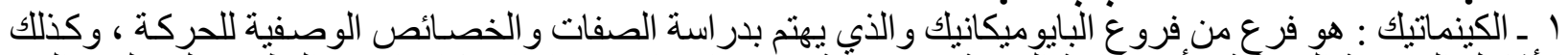

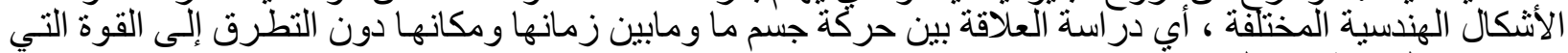

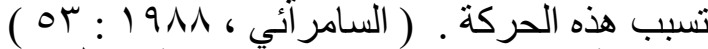

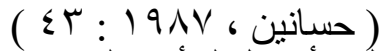

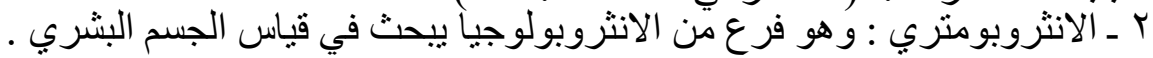

ب ـ التحليل الحركي : هو أحد العلوم الذي يعنى باستخدام الأسس و القو انين التي توضح الثكل الأفضانسل للأداء الحركي

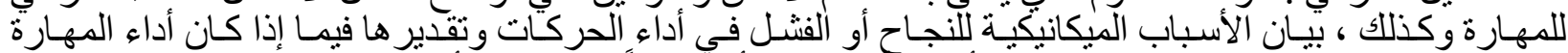

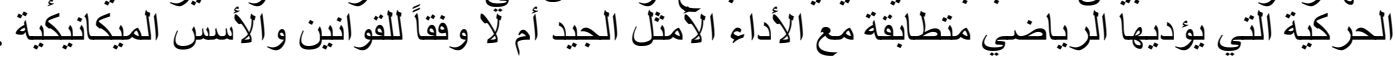




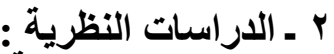

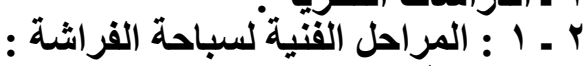

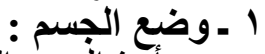

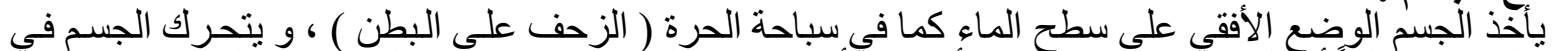

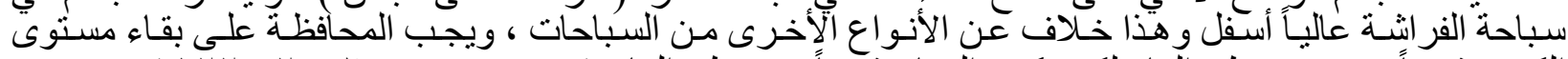

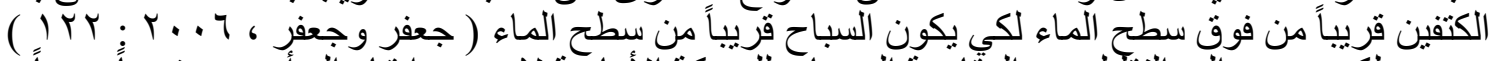

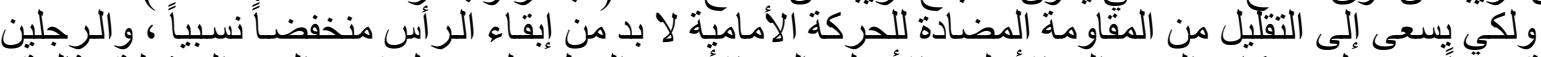

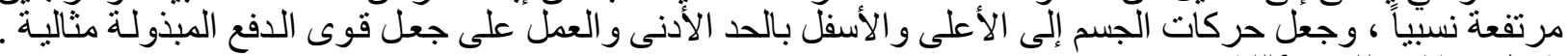

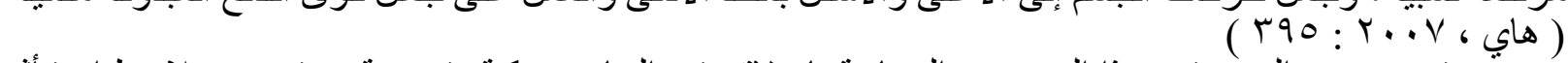

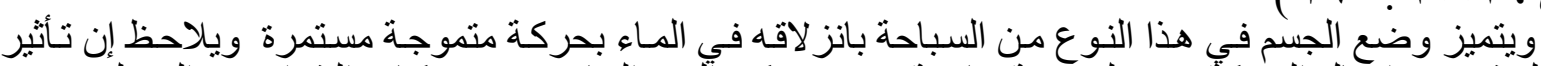

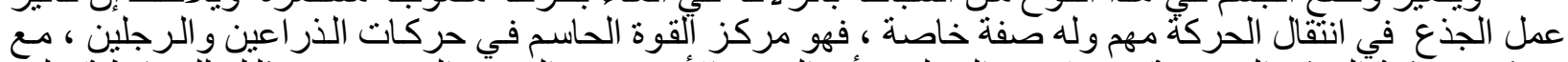

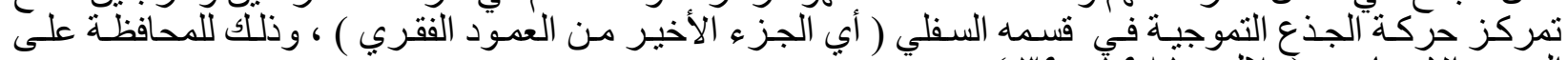

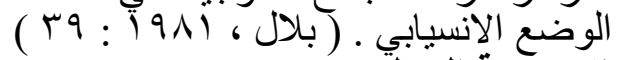

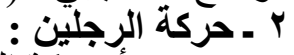

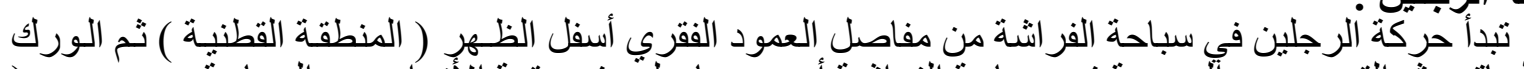

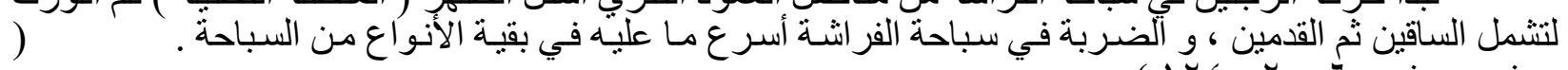

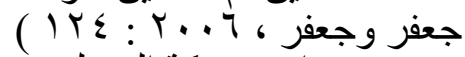

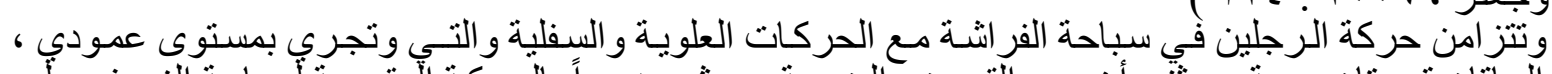

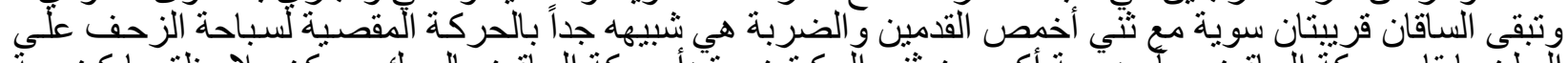

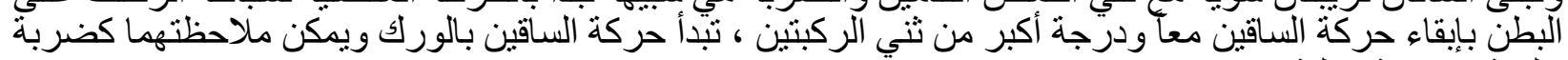
( Lunn Hogarth and other ، 1998 : 149") علوية وضربة سفلية

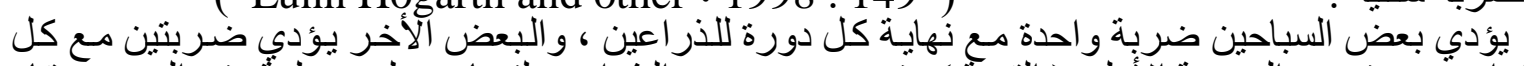

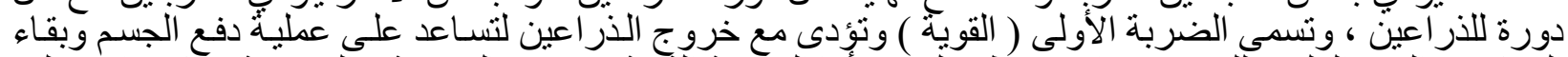

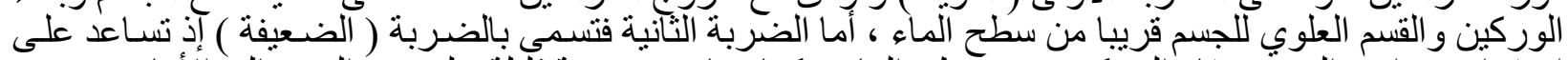

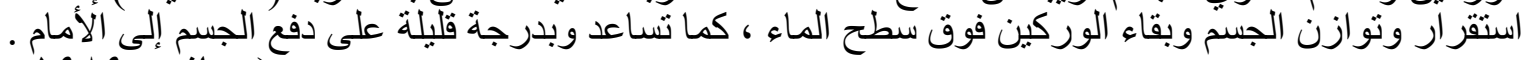

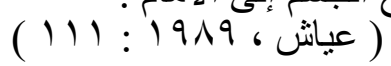

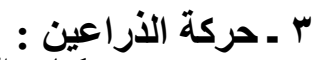

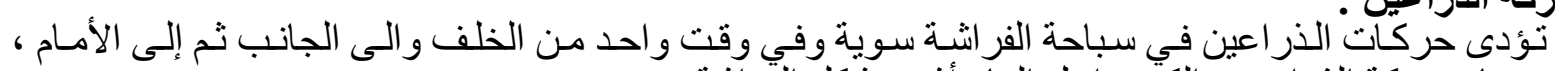

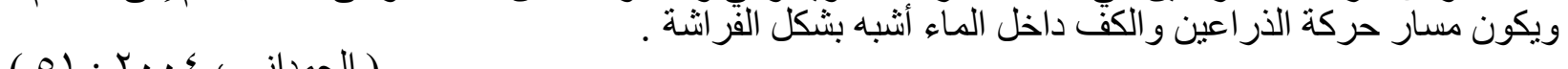

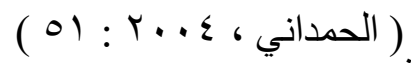

تقسم حركة الذر اعين في سباحة الفر اثنة إلى ثلاث مر احل وحسب الأسس الحركية وهي : الحدات

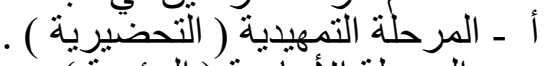
ب ـ المرحلة الأساسية (الرئية (التئة ) .

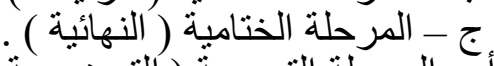

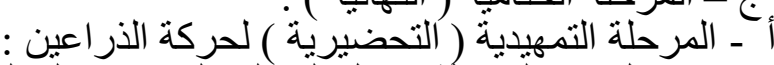

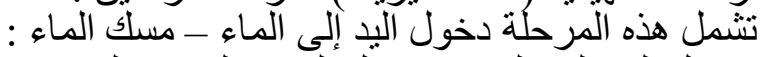

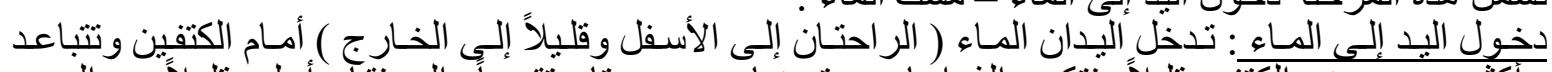

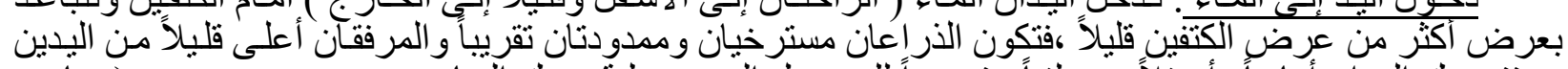

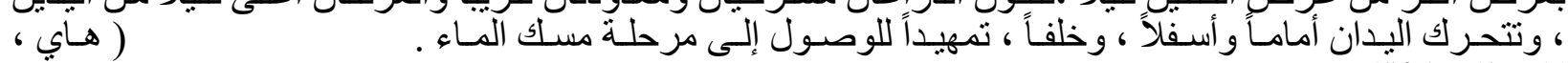

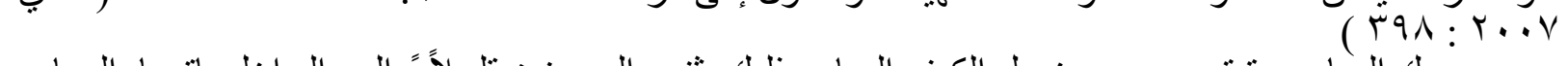

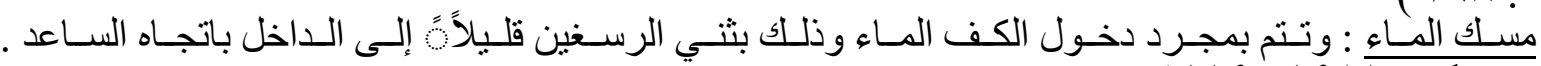

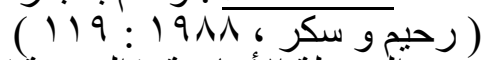

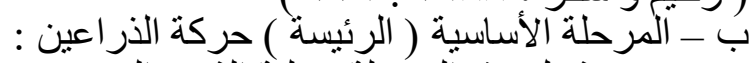

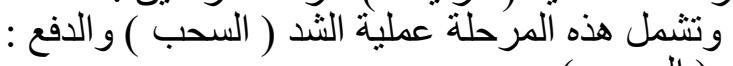

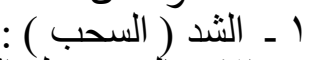

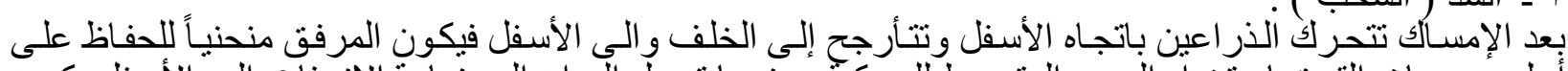

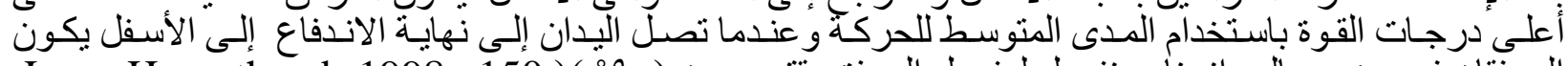

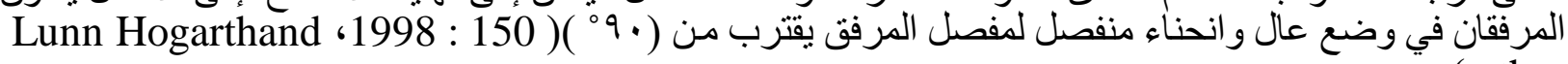
( other

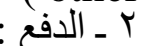

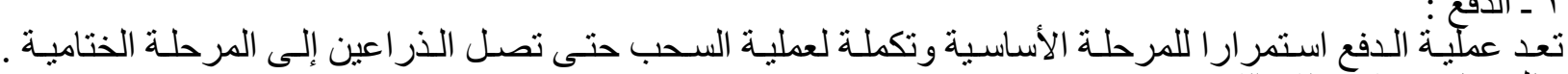

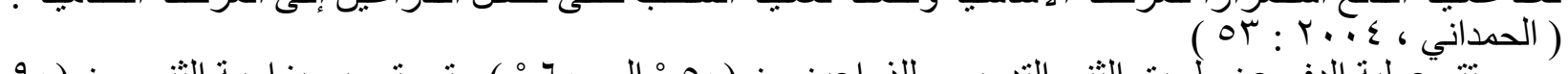

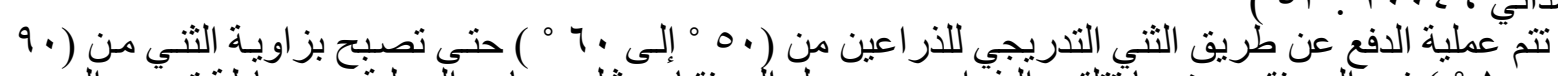

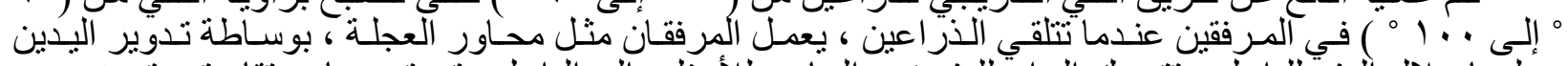

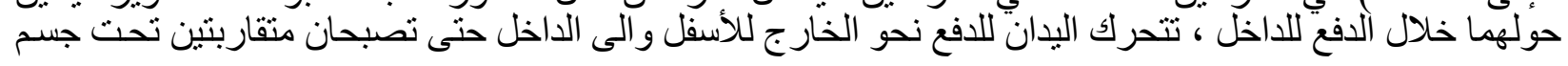




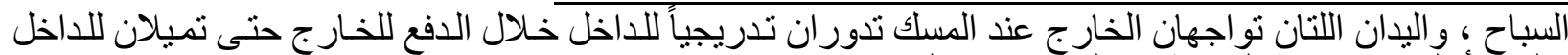

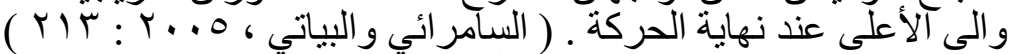

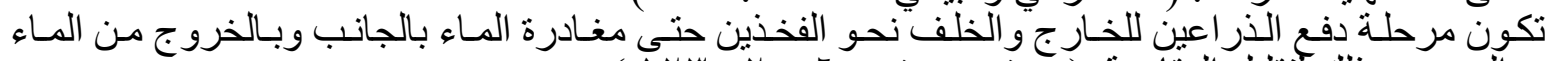

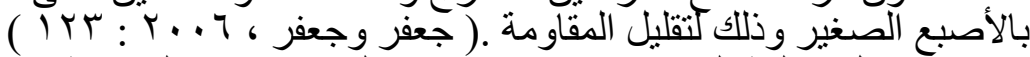

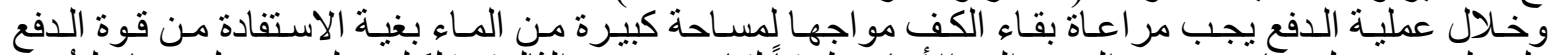

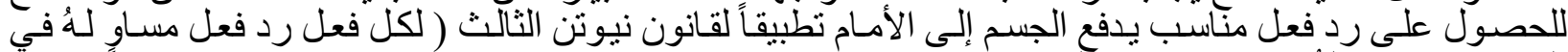

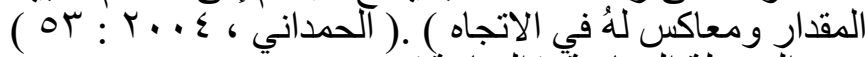
ج - المرحلة الختامية ( النهائية ) : الأهاه

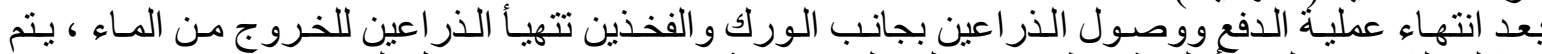

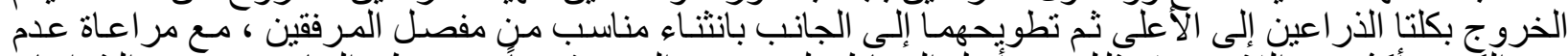

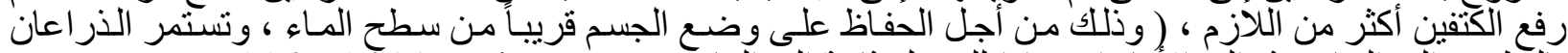
بالتطويح إلى الجانب ثم إلى الأمام استعدادا للاخول ثنانية إلى الماء. . ( رحيم و سكر ، 1911 ( ؛ : التنفس :

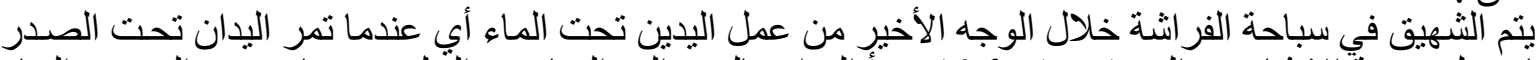

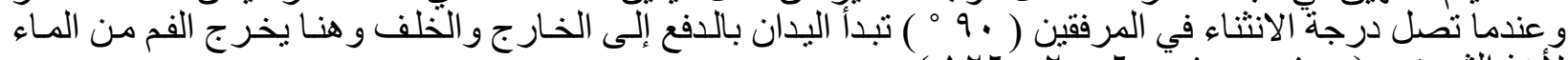

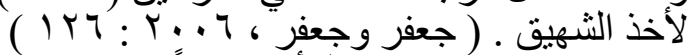

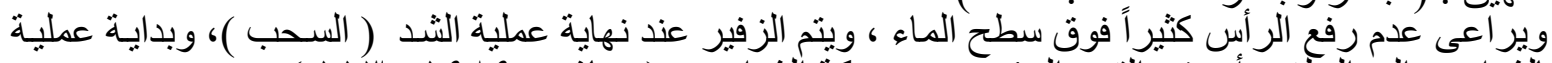

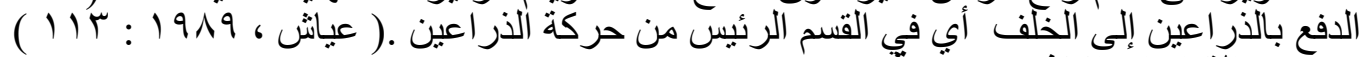

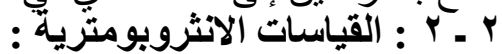

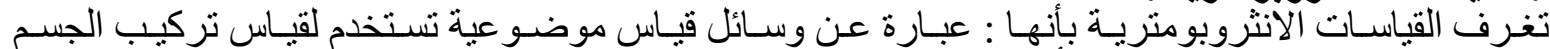

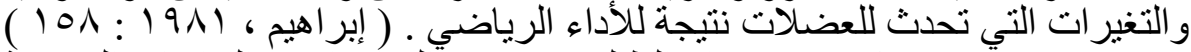

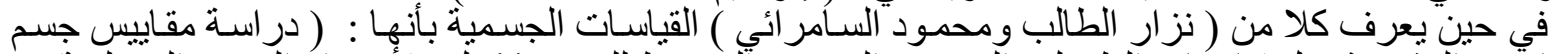

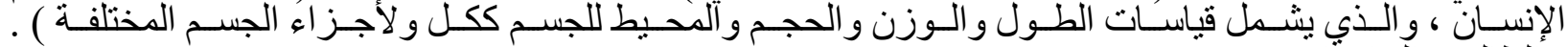

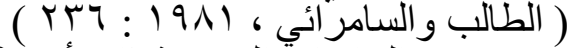

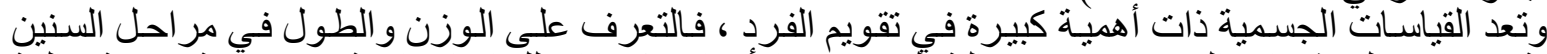

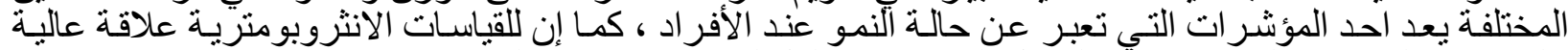

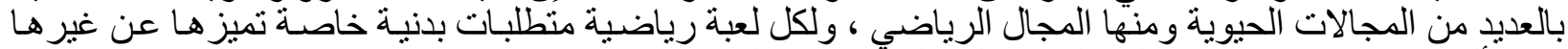

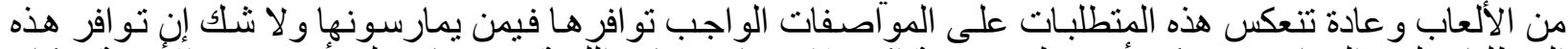

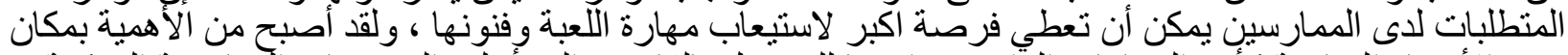

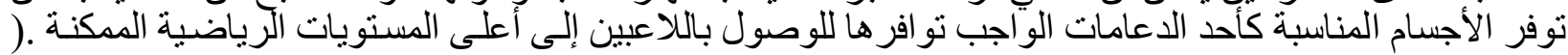

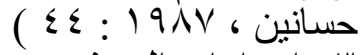

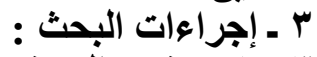

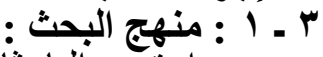

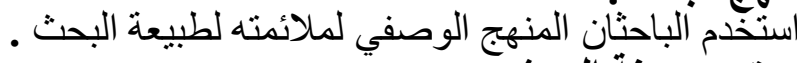

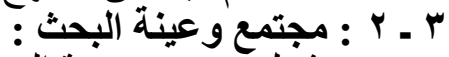
شمل مجتمع و عينة البحثث على سباحي منتخب محافظة نينوى فئة المتقدمين مكون من ( خمسـة ) سباحين ، أختيرو بالطريقة العمدية ، و الجدول رقم ( 1 ) يبين مو اصفات عينة البحث :

الجدول رقم ( 1 ( ) يبين مواصفات عينة البحث

\begin{tabular}{|c|c|c|c|c|c|c|c|c|c|}
\hline الكف & الساعد & العول & (الذراع & الكلي الطول & كتلة & خارج الجسم & (سنة) & \multicolumn{2}{|c|}{ اللاعبين } \\
\hline IV & ro & $r$. & vr & $1.7 \mathrm{~V}$ & r. १.. & ov & rI & امجد حاتم & 1 \\
\hline 11 & rq & r. & $v \varepsilon$ & 1.79 & r.ovI & 97 & $r$ & براء طارق & $r$ \\
\hline IV & rA & r & VA & $1 . v \mathrm{~V}$ & $0 . \cdot r \mu$ & VA & ro & حسان مصطفى & $r$ \\
\hline$r \cdot$ & $r V$ & $\varepsilon \cdot$ & $\Lambda v$ & 1.14 & 0.vvo & $\Lambda \varepsilon$ & r. & عثمان إبراهيم & $\varepsilon$ \\
\hline
\end{tabular}




\begin{tabular}{|c|c|c|c|c|c|c|c|c|c|}
\hline rI & rV & $\varepsilon$. & $\Lambda$ & 1.11 & $0 . r v a$ & $\wedge$. & ro & علي إبراهيم & $\bullet$ \\
\hline 11.9 & หq. & r६. & $\operatorname{va.1}$ & $1 . v \mathrm{~V}$ & $\varepsilon . \varepsilon 79$ & vr & rY.A & الوسط الحسابي سَ & \\
\hline $1 . \wedge 1$ & $1.1 \varepsilon$ & $0 . \cdot v$ & V.rq & $\because .9$ & $1 . r 91$ & 11.11 & r.YA & الانحراف المعياري 土ـع & \\
\hline Q.vr & $\varepsilon . r q$ & IE.V & Q.rY & $0 . \cdot 1$ & YA.91 & $10 . r 1$ & 1. & معامل الاختلاف & \\
\hline
\end{tabular}

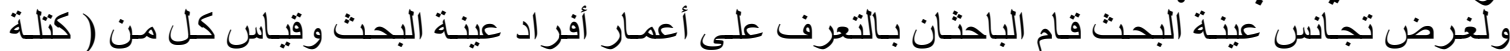

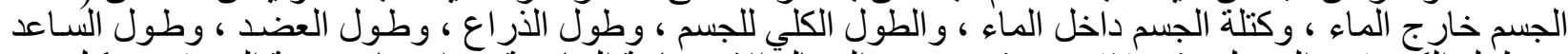

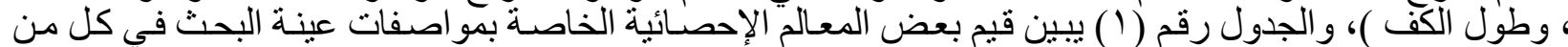

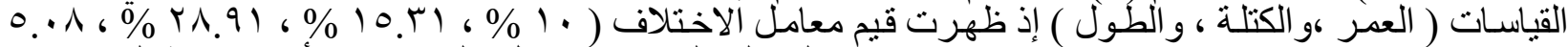

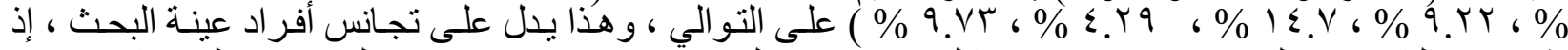

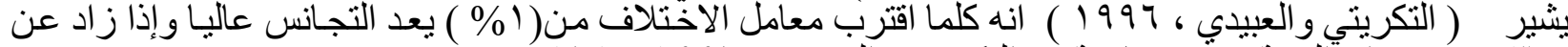

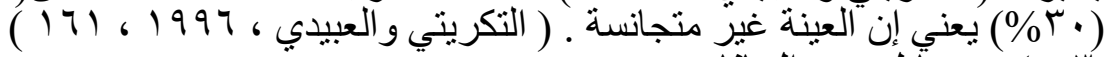

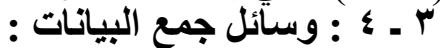

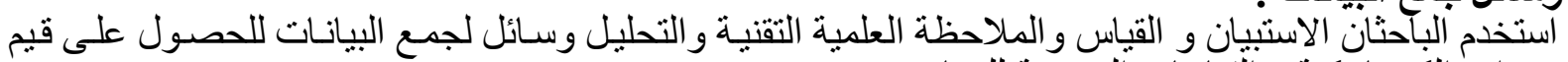
بعض المتغير ات الكينماتيكية و القياسات الجسمية للسباحين :

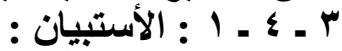

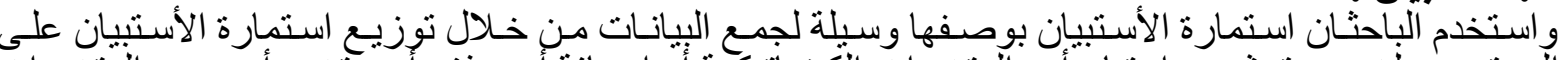

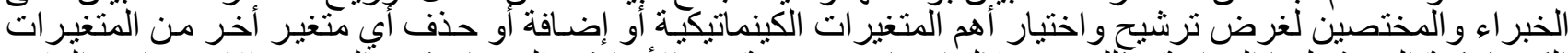

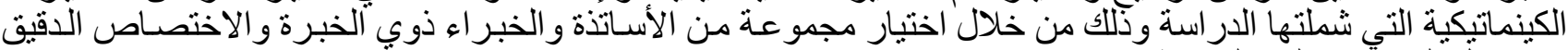

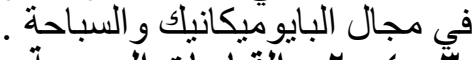

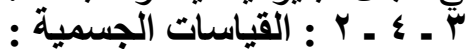
أ ــ الطُول ( سم ) :أستخدم الباحثان جهاز ( الر استامير ) لقياس الطول الكلي للجسم و شريط قياس لقياس أطو ال

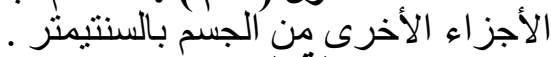

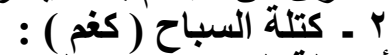

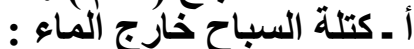

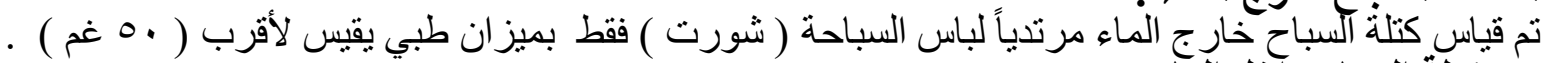

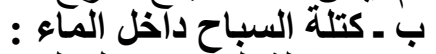
حسبت كتلة السباح داخل المل الماء من خلال المعادلة الآتية :

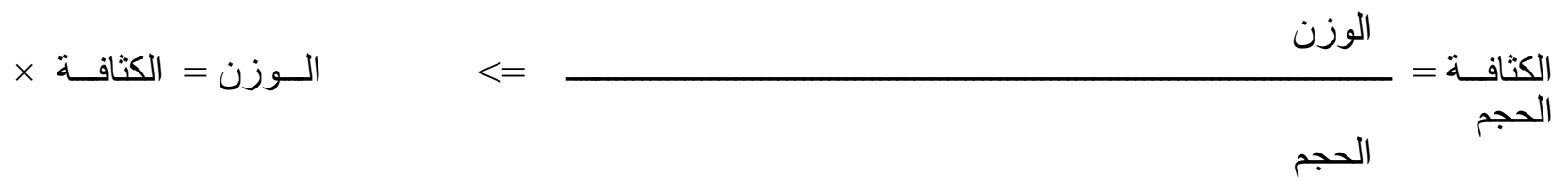

وزن الجسم في الهواء A . A الكثافة

$$
\text { وزن الجسم في الهواء - وزن الجسم في الماء }
$$

( 1 ( V R R

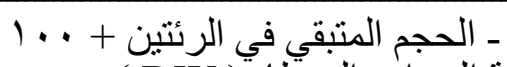

( V R )

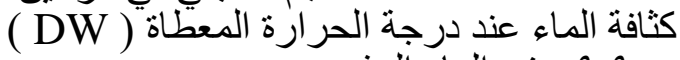

$$
\begin{aligned}
& \text { 9.9.9 في الماء العذب المباء } \\
& \text { r. • ا أ في الماء المالح }
\end{aligned}
$$

$$
\text { وزن الجسم في الهو اء - ـ وزن الجسم في الماء }
$$

كثافة الماء عند درجة الحرارة المعطاة ( DW )

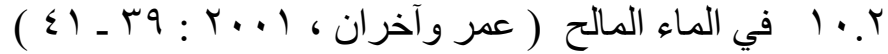

$$
\text { أذن : الكثافة = }
$$




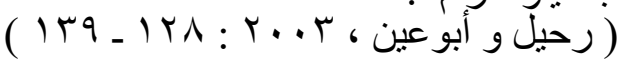 \\ 9.11}

ץ ـ ـ ـ ب : الملاحظة العلمية التقتية : (Sony Digital تصوير فيديوية داخل النماء ، والَّة تصوير أخرى محمولة توثيقية والثكل رقم (

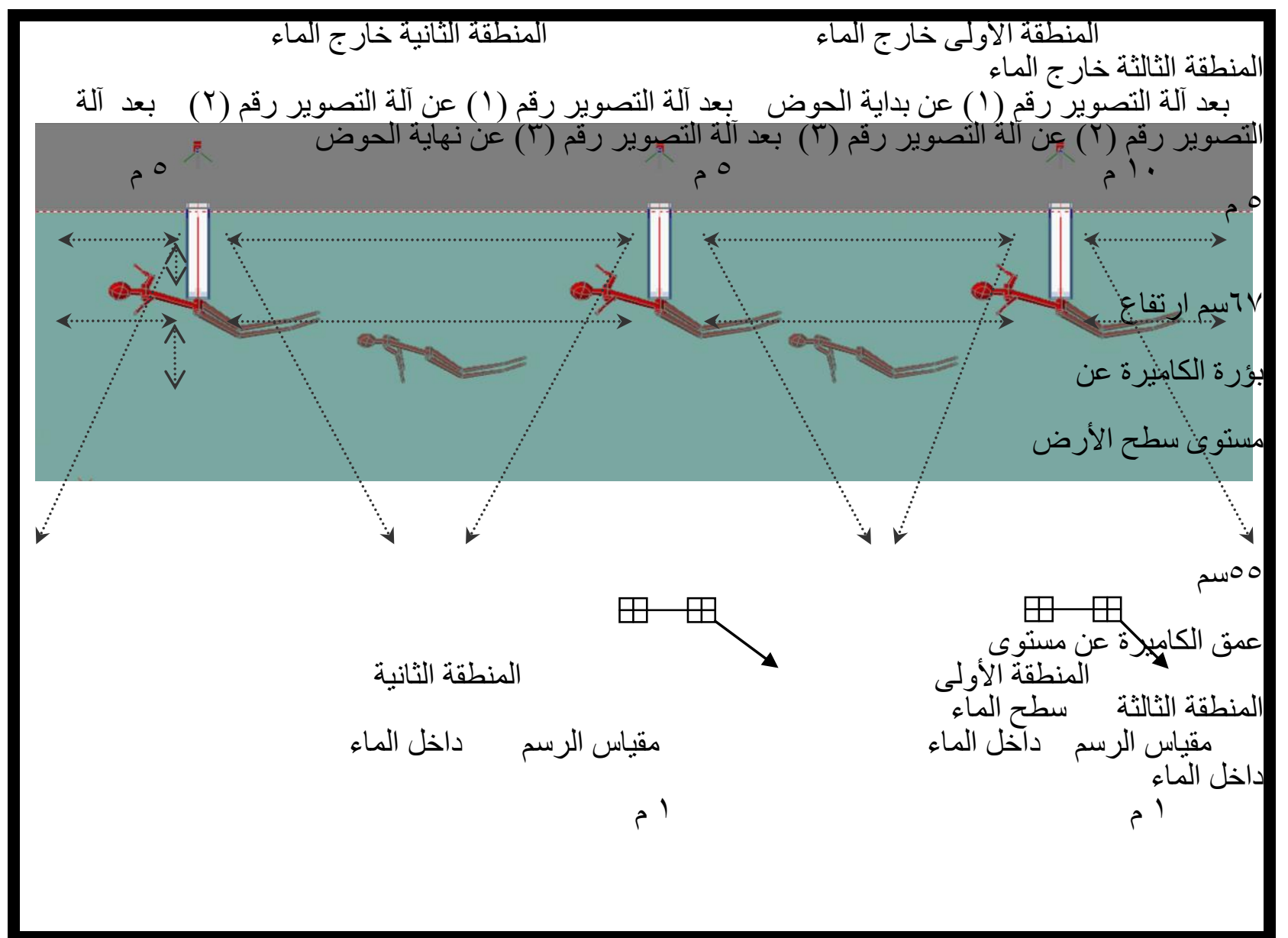

\section{الثزكل رقم ( ال) يوضح عملية التصوير ومواقع الات التصوير الفيديوية في التجربة النهائية}

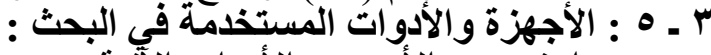

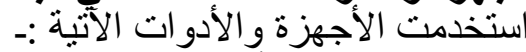

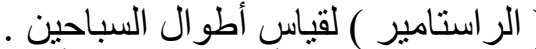

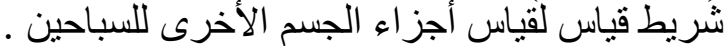

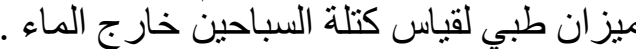

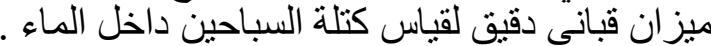

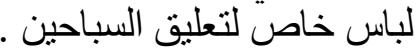

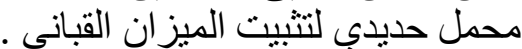

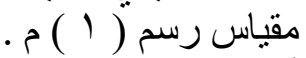

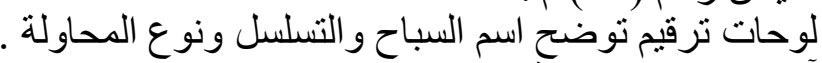

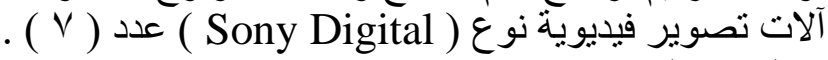

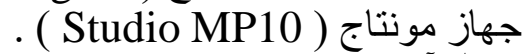

حامل آلات تصوير فيديوية عدد ( ) ) . 
• حافظات زجاجية عدد (r) ) .

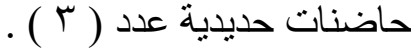

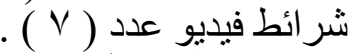

صافرة لإطلاق السباحين .

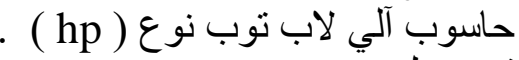

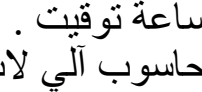
قرص ليزري .

قلم تلوين مضنّاد للماء لغرض الحصول على علامات إرشادية .

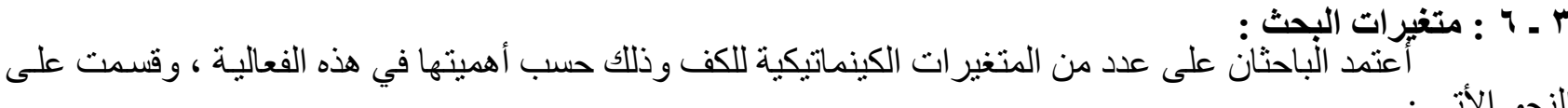

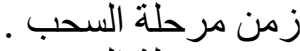

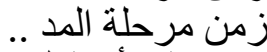

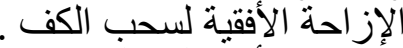

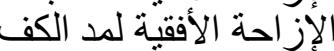

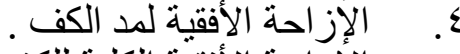

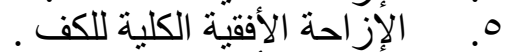

7.

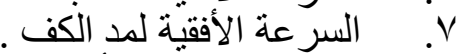

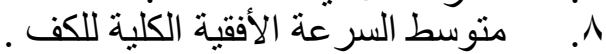

9.

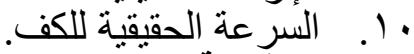

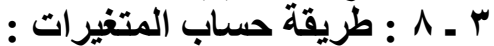

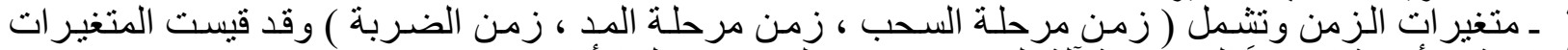

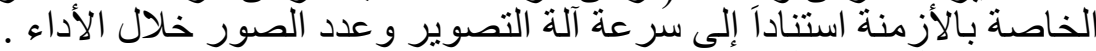

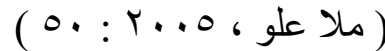

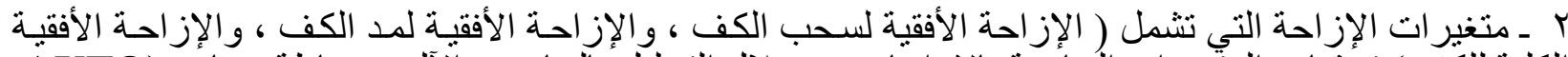

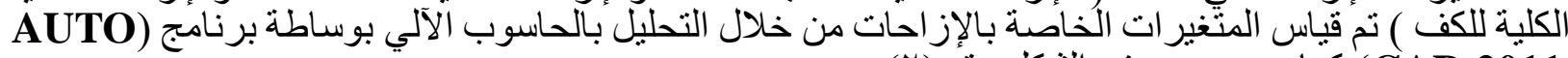

(r) كما هو موضنح في الشكل رقان (CAD 2011

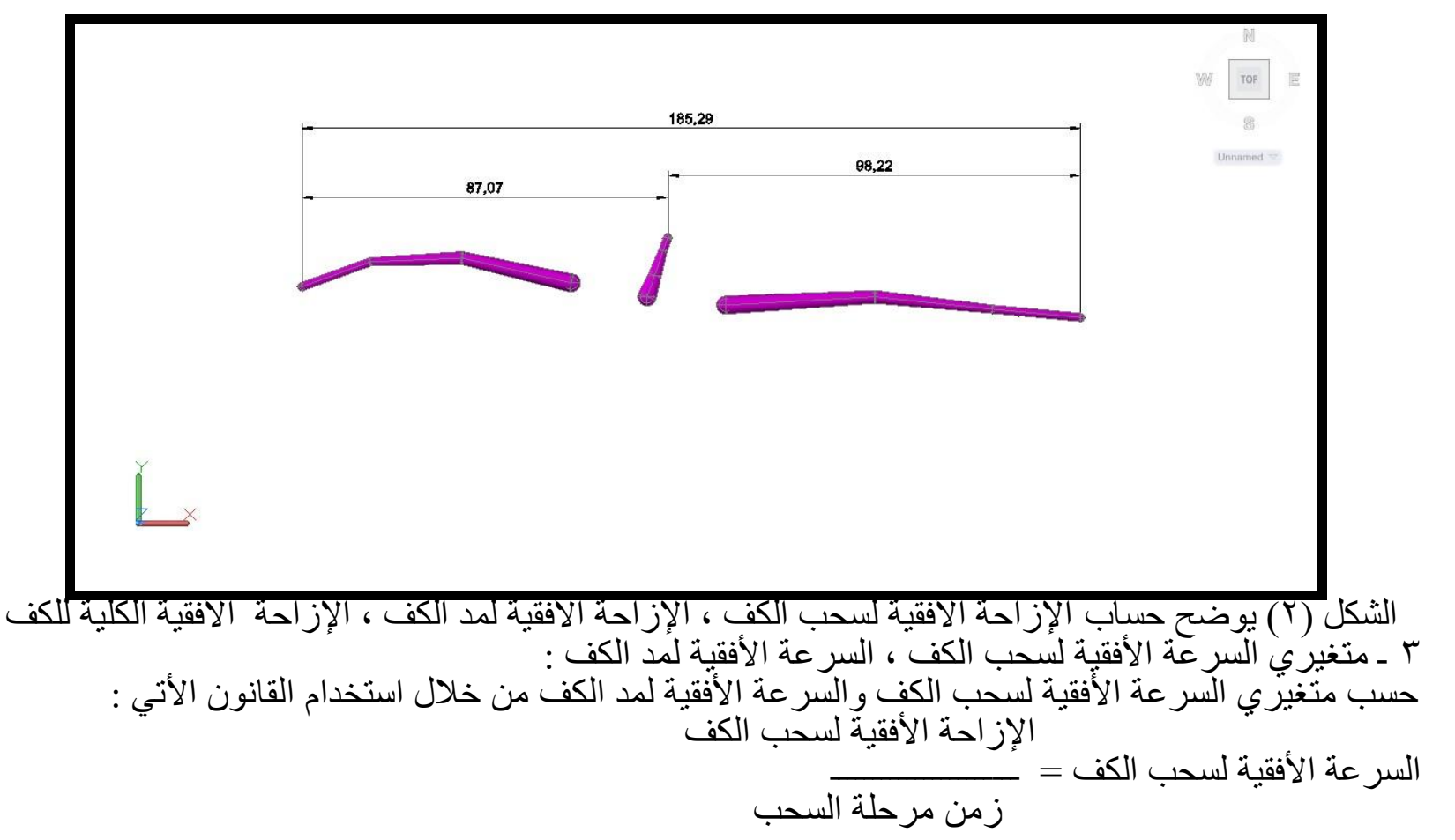



و السر عة الأفقية لمد الكف

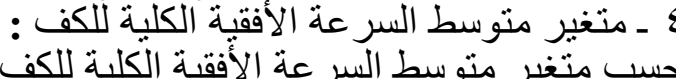

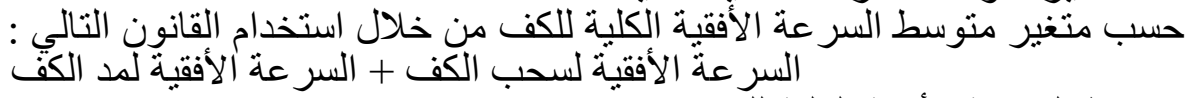

متوسط السر عة الأفقية الكلية للكف =

( التكريتي و العبيدي ، 1997 : ب. (1)

ه ـ متغير المسافة الحقيقية للكف :

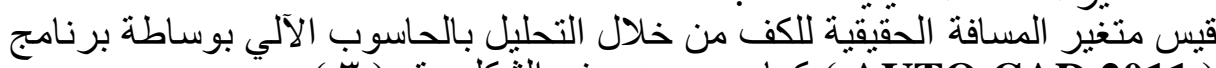
(AUTO CAD 2011 ) كما هو موضح في الثكل رقم (T) ( )

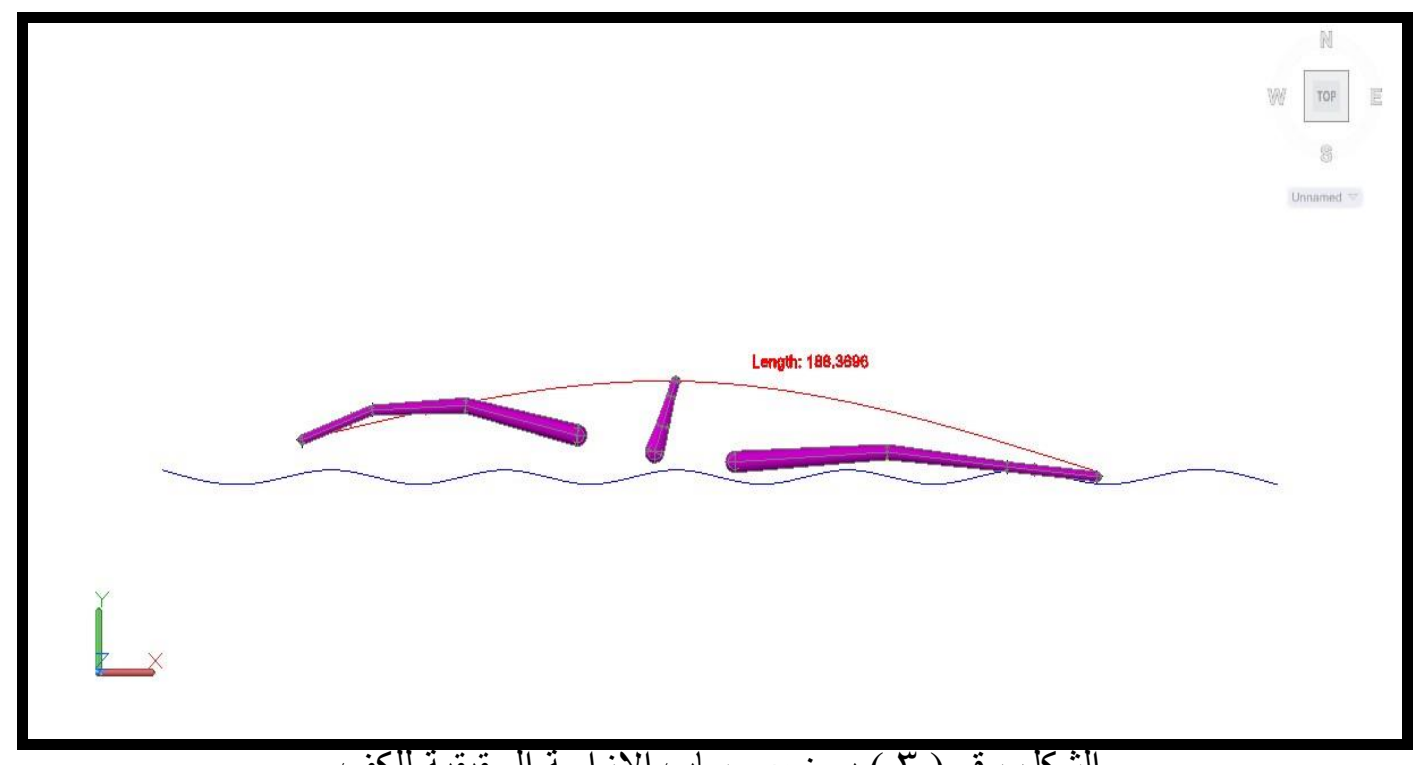

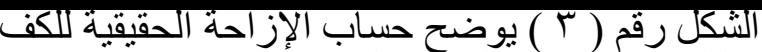

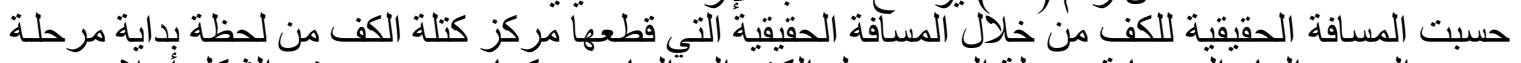

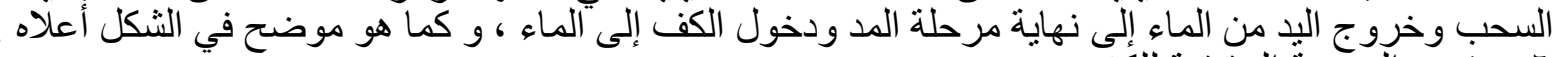

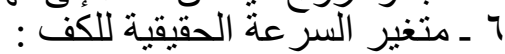

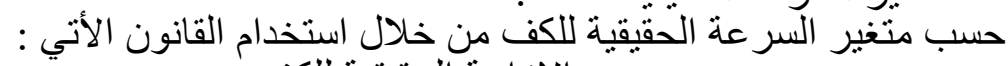
الإزاحة الحقيقية للكف الخف

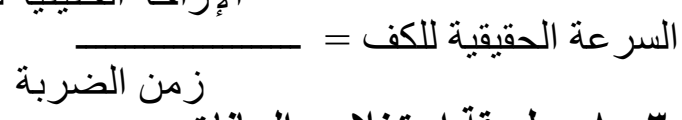

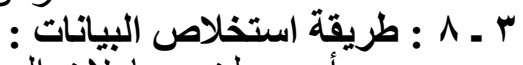

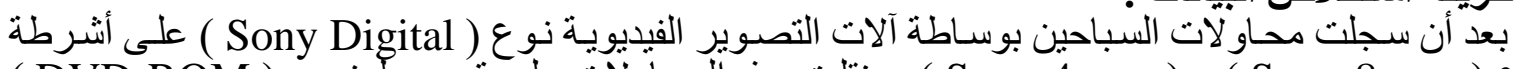

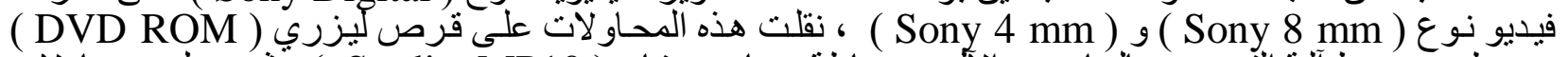

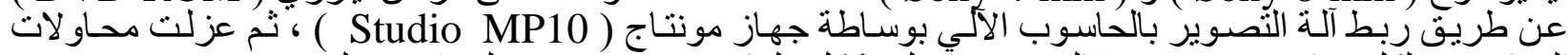
السباحين ولكل سباح بمفرده من خلال وضعهاً على شكل ملفات ( Folders ) على قرص ليزري (DVD ROM) 


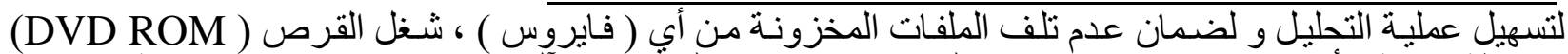

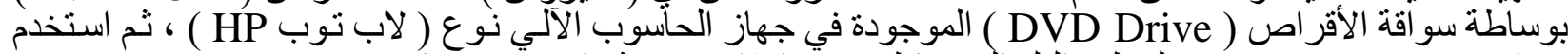

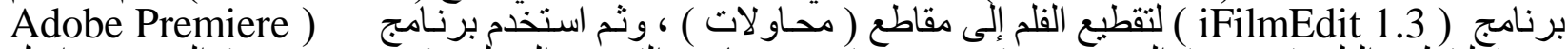

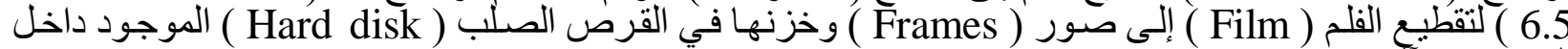

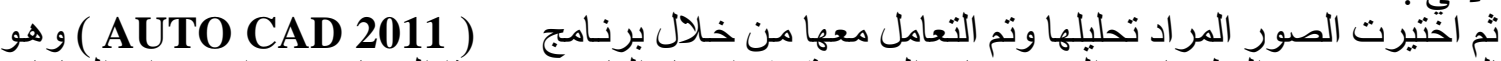

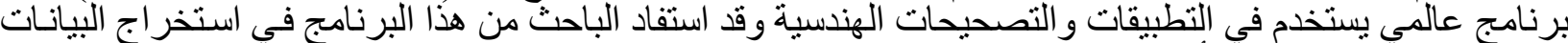

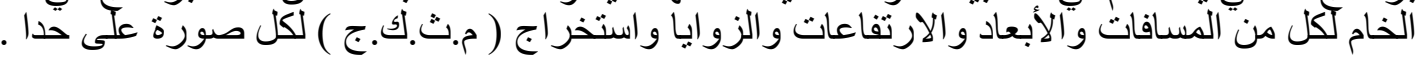

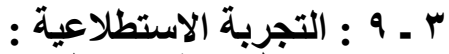

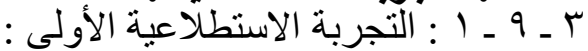

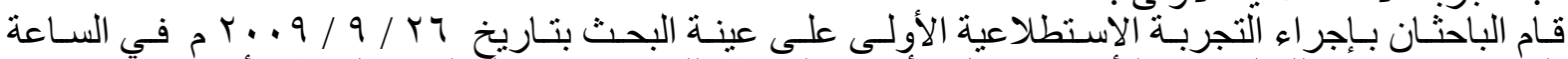

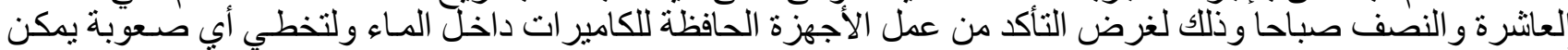

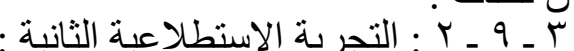

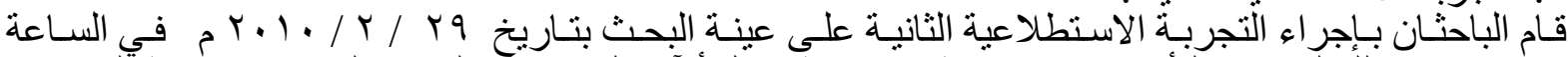

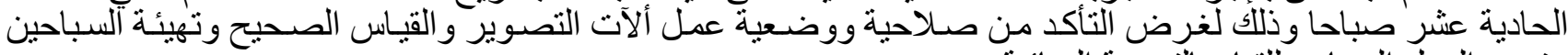

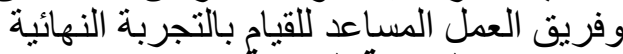

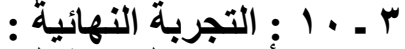

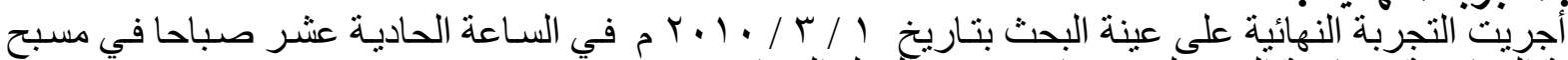

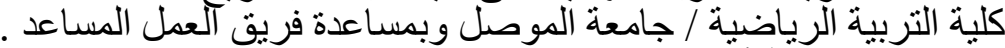

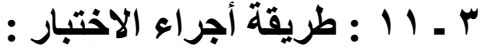

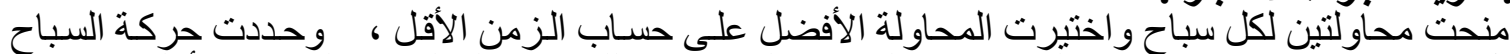

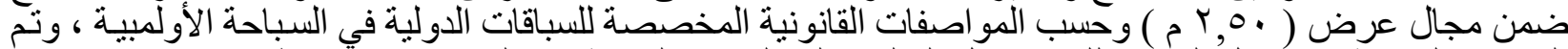

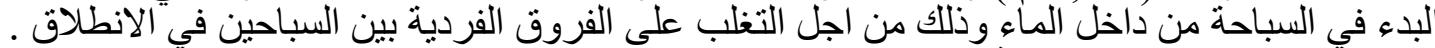

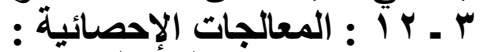

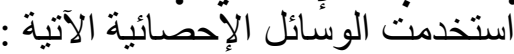

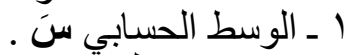

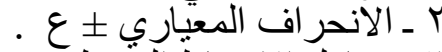

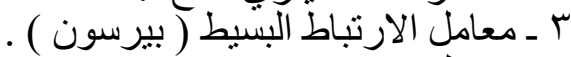

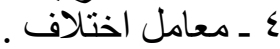

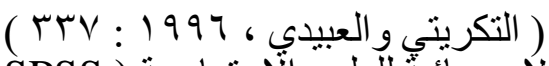

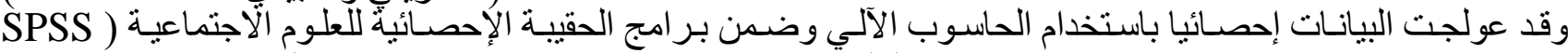

(Sabine and Brian , 2004 : 10 - 14 )( Statistical Package of Social Science or

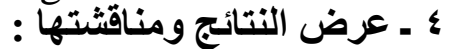

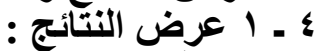

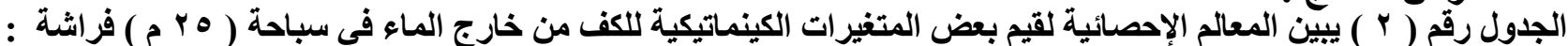

\begin{tabular}{|c|c|c|c|c|c|}
\hline الإزاحة الأفقية & الإزاحة الأفقية & لإلزاحة الأفقية & زمن مرحلة المد ( ثا & زمن مرحلة السحب & تسلسل اللاعبين \\
\hline I,IVY & r & $\bullet, 0 \varepsilon$. & $\cdot, \mid r$. & e, Ir. & 1 \\
\hline 1,100 & $\cdot, 7 \varepsilon q$ & $\cdot .0 \cdot 7$ & $\cdot, \mid r \cdot$ & $\bullet, \bullet \bullet$ & $r$ \\
\hline $1, \mathrm{r} \wedge \mathrm{q}$ & $\cdot, \mathrm{V} \times$ & • & $\bullet, \wedge \bullet$ & $\cdot, \mid r$. & $r$ \\
\hline 1,870 & $\cdot, r \cdot r$ & •, Аาะ & $\cdot, 1 \%$. & $\cdot, 17$ & $\varepsilon$ \\
\hline 1,017 & $\cdot, 917$ & $\cdot, \wedge \cdots$ & $\cdot, \mid r \cdot$ & $\cdot, r \cdots$ & $\bullet$ \\
\hline $1, r v a$ & •,vir & צד & $\cdot, \| 1 Y$ & q & الوسط الحسابي \\
\hline • ו ו & 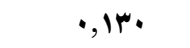 & $\cdot, 109$ & $\cdot, \cdot 11$ & $\cdot, \cdot \varepsilon q$ & الانحراف المعياري \\
\hline
\end{tabular}

الجدول رقم ( ب )يبين المعالم الإحصائية لقيم بعض المتفيرات الكينماتيكية للكف من خارج الماء في سباحة ( ه م م ) فراشة :

\begin{tabular}{|c|c|c|c|c|c|}
\hline السرعة الحقيقيا & للمسافة الحقيقية & متوسط السرعة الأفقية & السرعة الأفقية & السرعة الأفقية & تسلسل اللاعبين \\
\hline
\end{tabular}




\begin{tabular}{|c|c|c|c|c|c|}
\hline ( م/ثا ) & $(p)$ & ) & ( م/ثا ) & ( م/ثا ) & \\
\hline $0,0 \cdot Y$ & $1, r r$. & $\varepsilon, \wedge \wedge 1$ & 0, Y74 & $\varepsilon, \& 9 V$ & 1 \\
\hline $0,71 \wedge$ & $1, r \leqslant \Lambda$ & $0 . \Lambda \% V$ & $0,8 \cdot 9$ & T,MYO & $r$ \\
\hline $9,01 Y$ & 1,orr & V.rAo & 9.7 & $0,1 v$. & $r$ \\
\hline $0, v \theta \varepsilon$ & 1,711 & $0, r \mu \varepsilon$ & $0, \cdot 17$ & 0, rav & $\varepsilon$ \\
\hline$v, \cdots v$ & 1,974 & 0.119 & V,TrY & $\varepsilon, \cdots$ & 0 \\
\hline $9, \cdot \vee q$ & 1,071 & $0 . \wedge r q$ & $9.01 \varepsilon$ & $0 . \cdots v$ & الوسط الحسابي \\
\hline •, ror & $\cdot, Y \circ \Lambda$ & .901 & 1.910 & $\cdot . \wedge \wedge \vee$ & الانحراف المعياري \\
\hline
\end{tabular}

الجدول رقم ( ؛ )يبين المعالم الإحصائية لقيم بعض المتغيرات الكينماتيكية للكف من داخل الماء في سباحة ( ه ب م ) فراشة :

\begin{tabular}{|c|c|c|c|c|c|}
\hline الإزاحة الأفقية & $\begin{array}{c}\text { الإزاحة الأفقية } \\
\text { المد الكف } \\
\text { ( ) }\end{array}$ & 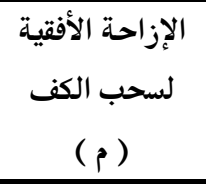 & زمن مرحلة المد ( ثا & زمن مرحلة السحب & تسلسل اللاعبين \\
\hline$\cdot, 0 \wedge 1$ & $\cdot, \cdot \Delta V-$ & •, マ৭ะ & $\cdot$, , • & .99 & 1 \\
\hline •, YN। & $\cdot, \cdot 90$ & •, YוT & $\cdot, r \cdot \cdot$ & $\cdot, \varepsilon \cdot$ & r \\
\hline$\cdot, \Delta \wedge \vee$ & $\cdot, \cdot \vee v 0-$ & •,01r & $\cdot, r \cdot \cdot$ & $\cdot,\{\varepsilon$ & $r$ \\
\hline •,VY乏 & $\cdot, \cdot 91-$ & איד, & $\cdot, r \varepsilon$. & $\cdot, \leqslant \varepsilon \cdot$ & $\varepsilon$ \\
\hline$\cdot$, Vฯ\& & $\cdot, \cdot V Y-$ & •, rar & $\cdot, r \cdot \cdot$ & $\cdot, \uparrow \cdot$ & 。 \\
\hline$\cdot .7 \leqslant 1$ & $\cdot, \cdot \leq q-$ & $\cdot, 079$ & •, rY & $\cdot, \Delta \wedge \varepsilon$ & الوسط الحسابي \\
\hline - TrM & • & •, Yrr & •, & • & الانحراف المعياري \\
\hline
\end{tabular}

الجدول رقم ( • ) يبين المعالم الإحصائية لقيم بعض المتغيرات الكينماتيكية للكف من داخل الماء في سباحة ( ه م م) فر اشة

\begin{tabular}{|c|c|c|c|c|c|}
\hline 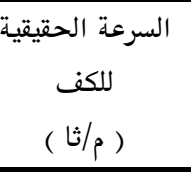 & | المسافة الحقيقية للكن & متوسط السرعة الأفقية & 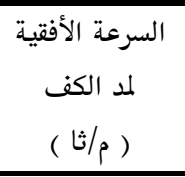 & 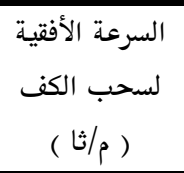 & تسلسل اللاعبين \\
\hline $1, .99$ & 1,rar & $\cdot .017$ & $\cdot, Y \cdot \xi-$ & $\cdot, \Lambda Y V$ & 1 \\
\hline 1, Vor & $1, \cdot 0 \varepsilon$ & $\left.\cdot, \sum\right\rceil \uparrow$ & •,rro & • orq & $r$ \\
\hline $1, \wedge 11$ & 1,109 & $\cdot, \mathrm{vV}$ & $\cdot, r \vee O_{-}$ & 1,170 & $r$ \\
\hline $1, v r q$ & $1,1 \wedge r$ & $\cdot, 9 \cdot 9$ & 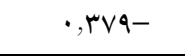 & $1, \varepsilon r q$ & $\varepsilon$ \\
\hline $1, r V Y$ & $1, r \cdot 1$ & $\cdot, 79$ & • & $1, \cdot 11$ & 0 \\
\hline 1,000 & 1,194 & $\cdot, 7 \times 1$ & $\cdot, 199-$ & $\cdot, 991$ & الوسط الحسابي \\
\hline$\cdot, r \cdot q$ & $\cdot, 111$ & •, rYI & $\cdot, r \cdot r$ & $\cdot, r \leqslant$. & الانحراف المعياري \\
\hline
\end{tabular}

الجدول رقم ( 7 ) يبين علاقة الارتباط بين قيم بعض المتغيرات الكينماتيكية للكف من خارج الماء مع طول الكف لاى عينة البحث

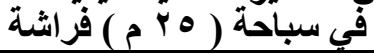

\begin{tabular}{|c|c|c|c|c|c|}
\hline الإزاحة الأفقية & الإزاحة الأفقية & لالإزاحة الأفقية & زمن مرحلة المد ( ) ما ) & زمن مرحلة السحب ( ثا ) & المتغيرات \\
\hline
\end{tabular}




\begin{tabular}{|c|c|c|c|c|c|}
\hline$\cdot . \Delta r \cdot$ & $\cdot \varepsilon r V$ & $\cdot . \wedge \varepsilon 1$ & - .sQY & $\cdot . A Y I$ & طول الكف \\
\hline السرعة الحقيقية & 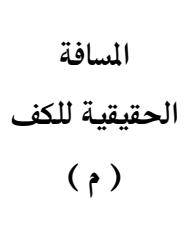 & متوسط السرعة الأفقية & الألمقية & لالأفقية & المتغيرات \\
\hline$\cdot .\{\Lambda 1$ & •.AYr & $\cdot .299$ & צחצ & $\cdot . \varepsilon \varepsilon$. & طول الكف \\
\hline
\end{tabular}

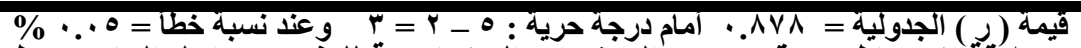

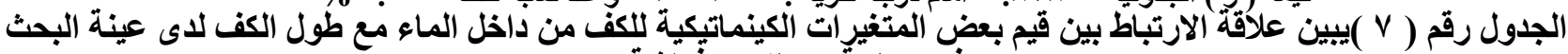

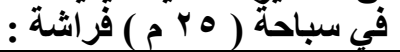

\begin{tabular}{|c|c|c|c|c|c|}
\hline الإزاحة الأفقية & $\begin{array}{c}\text { الإزاحة الأفقية } \\
\text { المد الكف }\end{array}$ & $\begin{array}{c}\text { لإزاحة الأفقية } \\
\text { لإحب الكف }\end{array}$ & زمن مرحلة المد ( ثا ) & زمن مرحلة السحب ( ثا ) & |المتغيرات| \\
\hline מצr & •rva - & $\cdot r \cdot r$ & $\cdot r V V-$ & $. .1 \mu \varepsilon-$ & طول الكف \\
\hline السرعة الحقيقية & 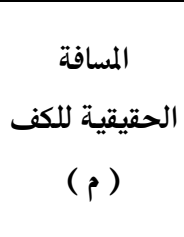 & متوسط السرعة الأفقيـة & اللمد الأفقية & ل السحب الكفية & |المتغيرات| \\
\hline$\because \cdots \wedge$ & $. .1 \% v-$ & .0 . & $\cdot r \cdot v_{-}$ & • & طول الكف \\
\hline
\end{tabular}

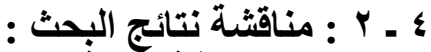

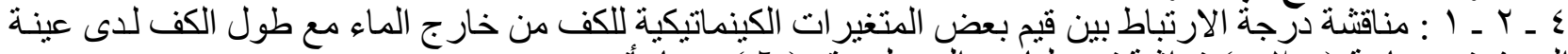

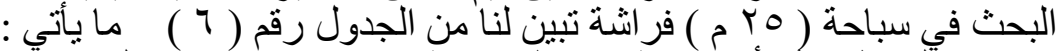

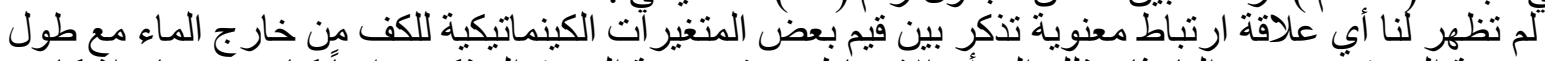

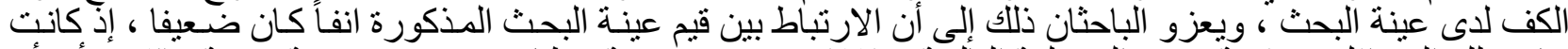

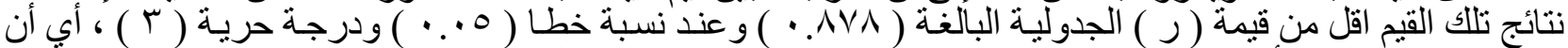

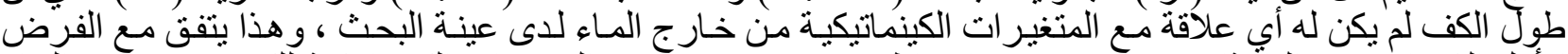

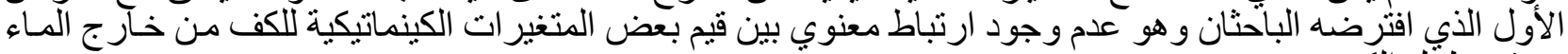

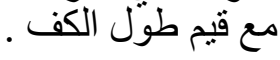

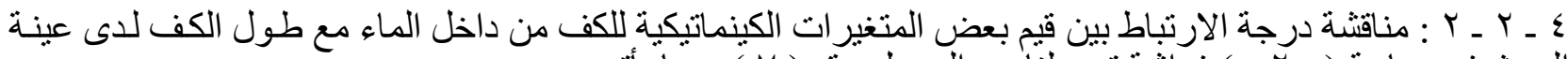

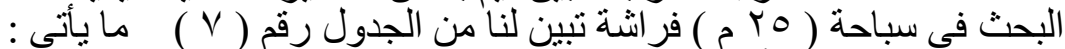

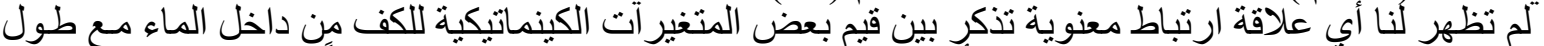

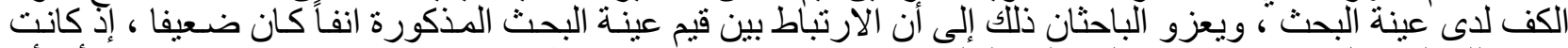

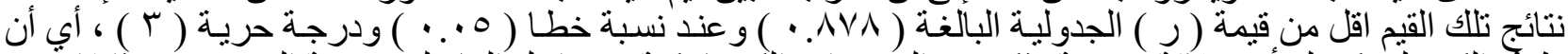

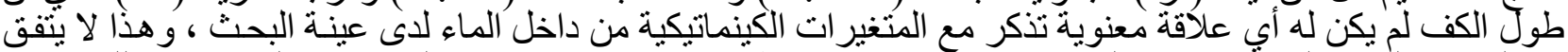

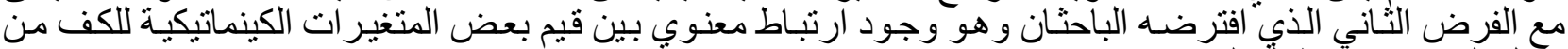

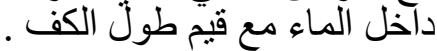

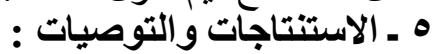

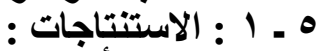

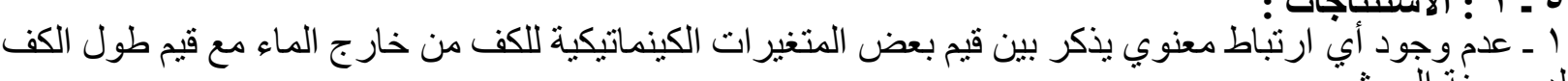


Y ـ عدم وجود أي ارتباط معنوي يذكر بين قيم بعض المتغير اتئ الكينماتيكية للكف من داخل الماء مع قيم طول الكف

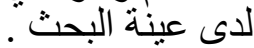

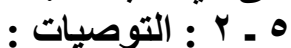

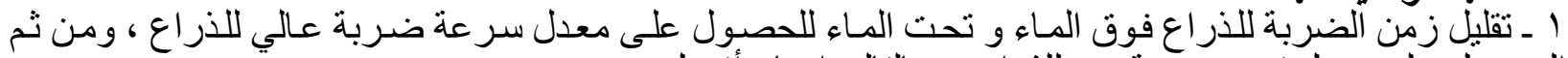

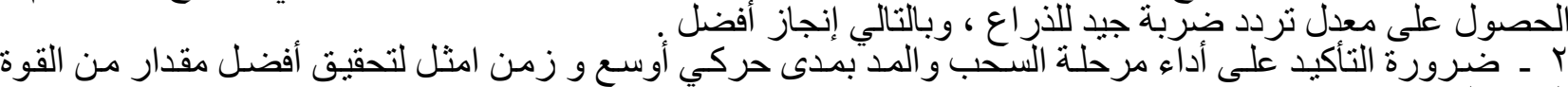

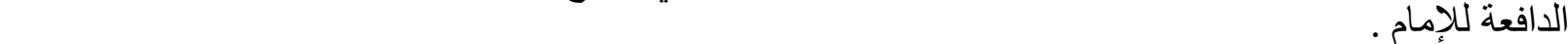
ب ـ اختيار السباحين ذوي المواصفات الجسمية المناسبة والتي تسهم في زيادة معدل السرعة ، و الحصول على انجاز أفضل . أختيار.

ـ ـ التأكيد على أن تكون راحة الكف مواجهة لقعر الحوض ألى ألد دخول البد إلى الماء مع مر اعاة ضم أصابع الكف

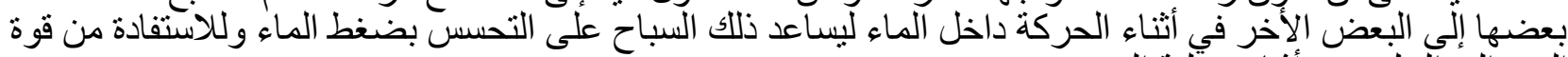

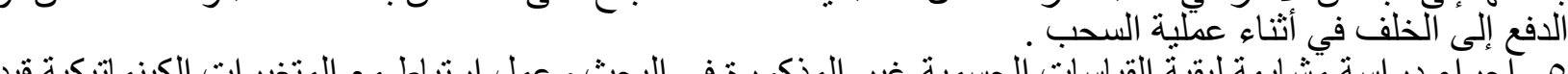

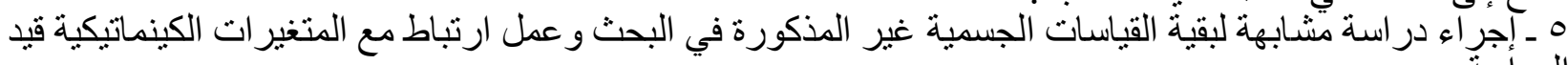

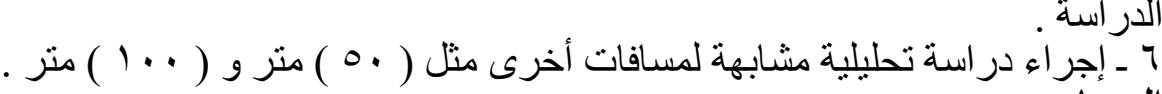

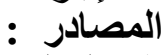

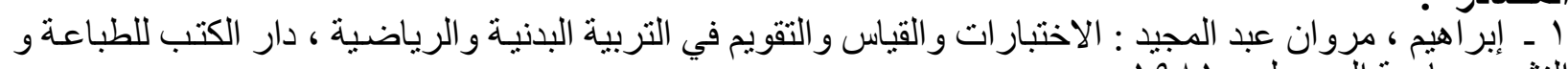

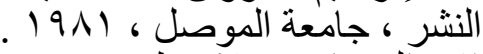

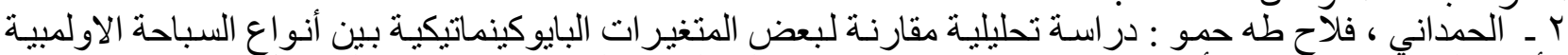

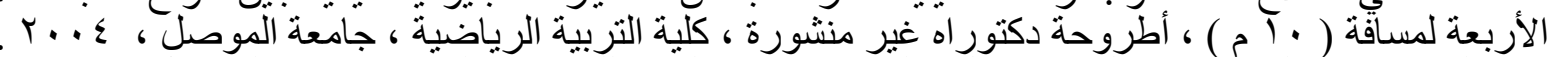

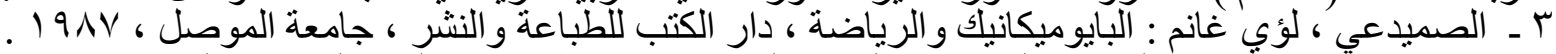

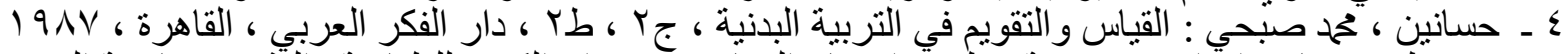

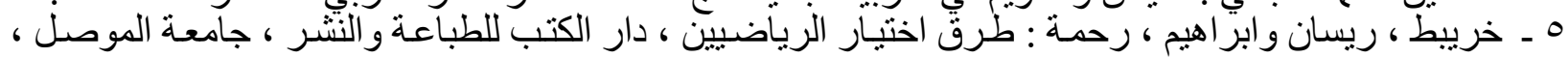
$19 \wedge \wedge$

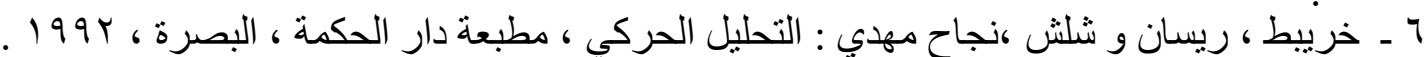

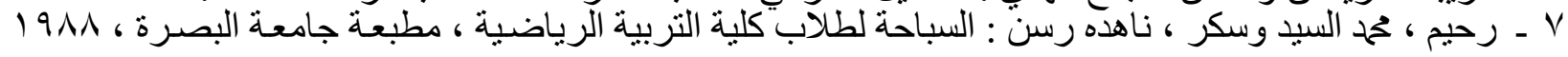

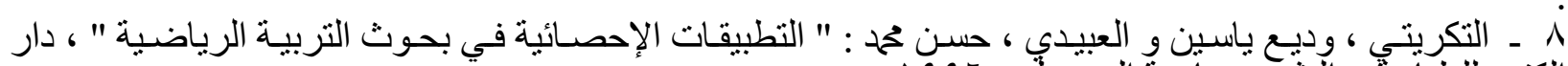

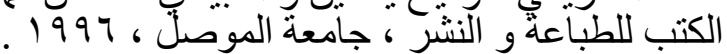

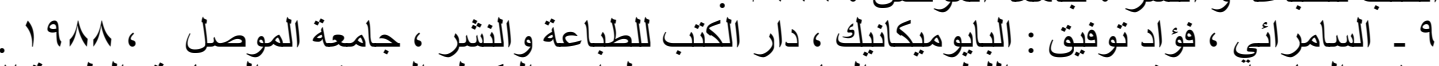

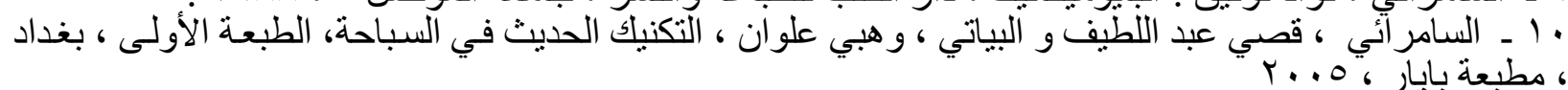

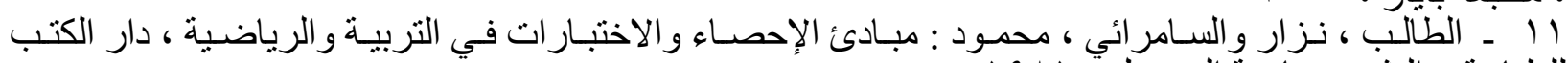

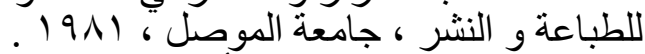

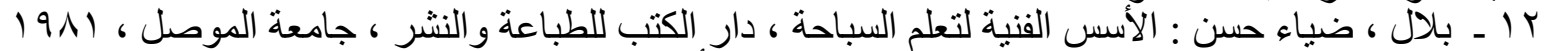

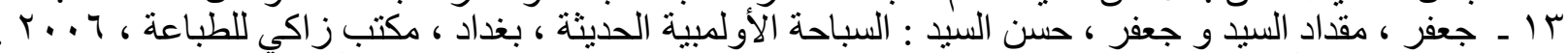

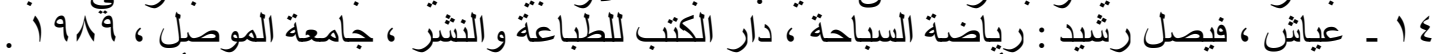

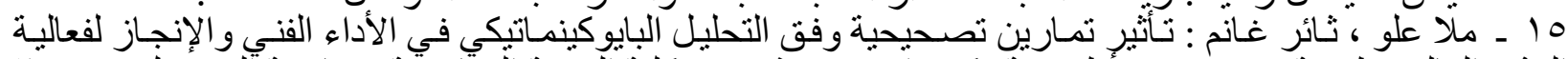

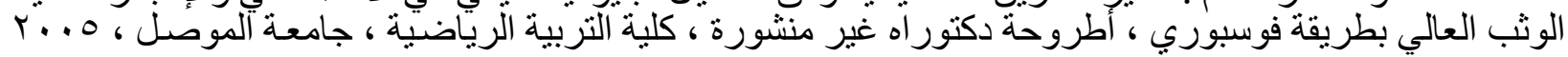

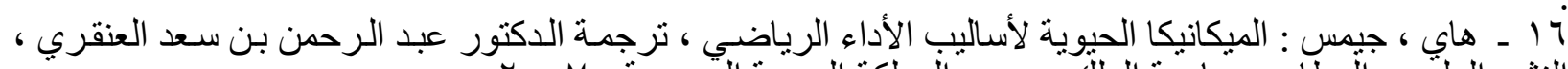

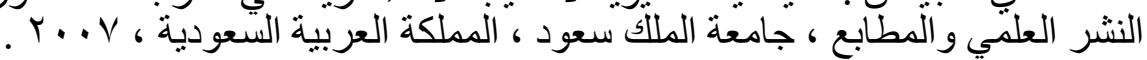
17 - Lunn Hogarth and other ; Swimming Teaching and Coaching, Level one, First Published, ASA Merchandising Ltd, 1998 .

18 - Sabine Landau \& Brian S ; A Handbook of Statistical Analyses Using SPSS ; USA , By Champman \& Hall CRC Pess , 2004. 